\title{
Notched Strength of Woven Fabric Kenaf Composite Plates with Different Stacking Sequences and Hole Sizes
}

\author{
Anders Hans Romayne ${ }^{1, *}$ and Hilton Ahmad ${ }^{1}$ \\ ${ }^{1}$ Department of Structures and Materials Engineering, Universiti Tun Hussein Onn Malaysia, 86400 \\ Parit raja, Batu Pahat, Johor, Malaysia.
}

\begin{abstract}
Advantages of using kenaf fibres over synthetic fibres in composites manufacturing are relatively cheap, less abrasive and hazardous during handling, and renewable materials. Current work investigates parametric effects on notched strength of woven fabric kenaf polymer composites plates with variation of lay-up types, notch sizes and plate thickness. Testing coupons are prepared using hand lay-up technique and circular notch were drilled prior to mechanical testing. Stress concentration at the notch edge promotes micro-damage event as tensile loading was applied leading to crack initiation and propagations across the plate width. It is suggested that woven fabric kenaf polymer composites are potentially used in low and medium load bearing applications.
\end{abstract}

\section{Introduction}

Applicability of Carbon Fibre Reinforced Polymer (CFRP) and Glass Fibre Reinforced Polymer (GFRP) in Malaysia is relatively limited as compared to other engineering materials and current supplies are generally imported, production of composite materials made from local-produced fibres (e.g. kenaf fibres) may reduce CFRP and GFRP dependency and wider its applicability to a greater extent. Kenaf fibres are relatively cheaper, lighter, renewable, recyclable, biodegradable and less abrasive compared to synthetic fibres. Excellent tensile strength and modulus of kenaf fibres were reported by previous researchers [1]. Previous works [2] reported promising results of un-notched strength of woven fabric kenaf composite plates. Research works on other natural fibres are aggressively ongoing in searching for utilizing natural fibre in composite materials that are renewable and sustainable. Tenth Malaysian Plan (RMK10) has highlighted to activate agricultural sector with high driven value and biotechnology in agricultural research leading to larger production of agriculture in near future. Woven fabric fibre composites had attracted much attention from engineers and scientist in various sectors due to several advantages such as drape ability, a woven fabric layer is equivalent to two unidirectional layers and excellent resistance against impact and fatigue. However, compared with unidirectional composites counterpart, existing of crimping region in woven fabric composites leading to strength and stiffness degradation but offset by the ability of woven

\footnotetext{
* Corresponding author: hilton@uthm.edu.my
} 
fabric to arrest crack growth and excellent fracture absorption at the tow crossover points. Combinations of weaving patterns, tow architectures and lay-up configurations lead to complexities of associated damage morphologies.

Comprehensive review of published literatures concerned with notched plates in composite materials and associated experimental observations has been presented [3-6]. Plates with discontinuities such as notch introducing stress concentrations at the vicinity of notch edge and different fracture and failure mechanisms are observed as compared with unidirectional (non-woven) lay-ups counterparts. Crack is initiated as the composite fracture toughness is exceeded and propagated along net-tension plane in self-similar manner until certain distance prior to catastrophic failure. The distance ahead the notch edge prior to catastrophic failure is known as process zone length where micro-damage event takes place. In a notched woven fabric GFRP composite subjected to remote tension, it has been shown experimentally using a model (transparent) GFRP system that prior to failure an intense zone of damage develops in the region of maximum tensile stress [4]. Damage within that zone comprises of matrix cracking, fibre-matrix splitting and fibre tow fracture. This approach is important to further the exploratory of plates associated with stress concentrations such as in bolted and welded joints [7-8].

Most of structures parts assembly requires discontinuity in the form of notches and cutouts for number of reasons. The failure mechanisms in composite materials are rather complex, experimental work need to be carried out to study in-depth the behaviour of these material when subjected to loading. Notched plates response to remote tensile loading is somewhat complex (even more complex with woven fabric fibres due to existing of crimp region) as micro-failure involved ahead of the notch tip, and strength prediction on notched plate had shown quite limited success [5]. There is no reported literatures on notched strength of woven fabric kenaf composites, current work concentrates on parametric study of notched strength woven fabric kenaf composite plates with variation of lay-up types, hole size and plate thicknesses under quasi-static loading. The experimental methodology includes woven fabric kenaf coupon preparation as designated in testing series, drilling of circular hole and conducting mechanical testing.

\section{Experimental works}

Figure 1 showed the flow chart of current experimental framework.

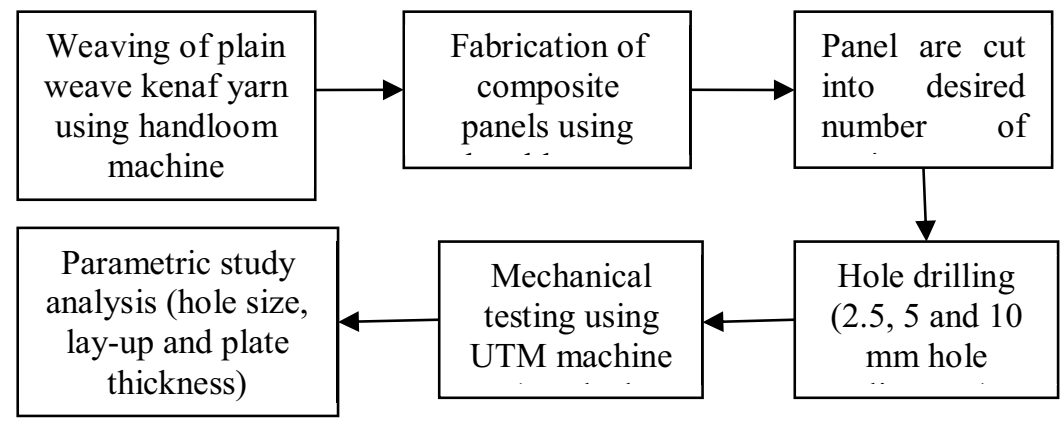

Fig. 1. Flow chart of experimental framework

Woven fabric layers were prepared using handloom weaving machine to required numbers as specified to testing series. Kenaf fibres are wrapped to avoid hairy fibre yarn as exposed to air and kept in UTHM Textile Laboratory. Current work use epoxy resin as matrix binder and fabricated using hand lay-up technique to produce composites lay-up panels. All 
fabricated panels were cut into testing coupon size using water-cooled saw and carefully cut to prevent any cracking failure along the coupon edge. Each testing coupons has $130 \mathrm{~mm}$ gauge length and plane width of $25 \mathrm{~mm}$ with varying notch sizes (i.e., open hole diameters), $d$, of 2.5, 5.0 and $10.0 \mathrm{~mm}$ giving $d / W$ ratios of $0.1,0.2$ and 0.4 respectively. End tab is prepared to provide better gripping and to avoid coupon slipping during mechanical testing. Hole drilling were carefully conducted with low helix and high speed and all notch length was inspected visually to ensure there was no defects were seen.

\section{Testing series}

Testing series of current work were given in Table 1 which comprised of variation combinations of hole size, lay-up types and plate thicknesses. Three testing coupons were prepared for each testing configurations, notched strength are averaged and given as $\sigma_{\mathrm{N}}=$ peak load $\left(P_{\max }\right) /[$ thickness, $t$ x plate width, $W$ ]. Mechanical testing were carried out using Instron 1175 machine 3369 with a crosshead speed of $0.5 \mathrm{~mm} / \mathrm{min}$ and $50 \mathrm{kN}$ load cell.

Table 1. Testing series under investigation in current work

\begin{tabular}{|c|c|c|c|}
\hline \multirow{7}{*}{ Weave type } & Orientation & Lay-up & Designation \\
\hline \multirow{4}{*}{ Plain Weave (PW) } & \multirow{3}{*}{ Cross-ply } & $(0 / 90)$ & PX1 \\
\cline { 3 - 4 } & & $(0 / 90 \mid 90 / 0)$ & PX2 \\
\cline { 3 - 4 } & \multirow{3}{*}{$\begin{array}{c}\text { Quasi- } \\
\text { isotropic }\end{array}$} & $(0 / 90 \mid 90 / 010 / 90 / 90 / 0)$ & PX4 \\
\cline { 3 - 4 } & \multirow{2}{*}{\begin{tabular}{c}
$(0 / 90|+45 /-45|-45 /+45 \mid 90 / 0)$ \\
\cline { 3 - 4 }
\end{tabular}} & $(60 /-60 \mid-60 / 60)$ & PQ4 \\
\cline { 3 - 4 } & & $(+45 /-45 \mid-45 /-45)$ & PT2 \\
\hline
\end{tabular}

\section{Results and discussions}

Figure 2(a) showed load-displacement profiles taken from data-logger that showed ultimate load of PX4 lay-up plates with different hole size. From the graph, the notched plate of woven fabric kenaf composite demonstrated a linear elastic behaviour until ultimate load and failure in a brittle manner. It is assumed that plastic deformation in tensile testing of notched plate is negligible, as found in other composite systems (Belmonte [4] and Manger [6]). Experimental observation found that a screeching sound were heard after few minutes testing, associated with matrix cracking and delamination occurred at its notch edge. Thereafter, fibre fracture occurred is an indicator of reaching peak load prior to catastrophic failure. Although this study did not measure the damage zone length (due to limited scope of current work), the existence of damage zone at vicinity of the notch has been reported by previous researchers [4-6].

Figure 2(b) showed an example of $5 \mathrm{~mm}$ hole size testing coupon at failure. As tensile force is applied, a crack has grown to approximately constant through the plate thickness across the net-tension plane (parallel to plate width). When the crack reached a critical length (associated with process zone length), catastrophic failure occurs ahead of the critical length. The size of damage zone length is approximately a size of radius hole. The 
notched strength decreased as hole size increased due larger remaining unloaded plate width, as expected. This also associated with smaller area of damage zone length developed at the hole vicinity prior to catastrophic failures as reported by Belmonte [4].

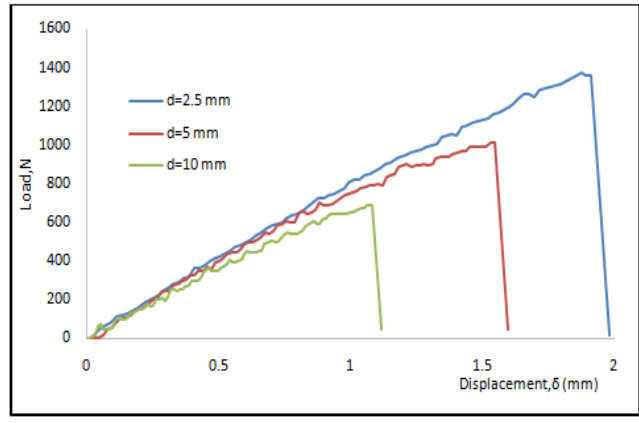

(a)

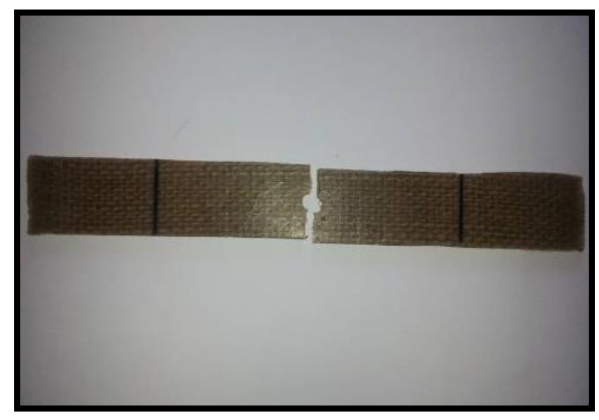

(b)

Fig. 2. (a) Load-displacement profiles of cross ply lay-up for PX4 for 2.5, 5 and $10 \mathrm{~mm}$ hole size Fig. (b). Photograph showing a laminate coupon of cross-ply lay-up containing $5 \mathrm{~mm}$ circular hole at failure.

As mentioned previously, increased notched strength with smaller hole size is expected due to larger unloaded region from the vicinity of the notch. It is also associated with the formation of damage zone length which formed perpendicularly to the loading direction. As composite material displayed brittle failure types, occurrence of damage formation at the hole vicinity can help the explanation of low strength on larger hole size. Belmonte [4] concluded interrupted test to confirm the occurrence of matrix cracking, delamination and numbers of tow fracture under scanning electron microscope (SEM). However, interrupted test and determination of damage zone length is not covered in the current scope. Notice that the hole size increments were doubled from $2.5 \mathrm{~mm}$ to $5 \mathrm{~mm}$ and correspondingly 5 $\mathrm{mm}$ to $10 \mathrm{~mm}$. About $10-20 \%$ strength reduction were observed with every increment of hole size. From PX series lay-up, it is also found that larger strength reductions were found in thicker plates. Similar trends were observed in all other lay-ups.

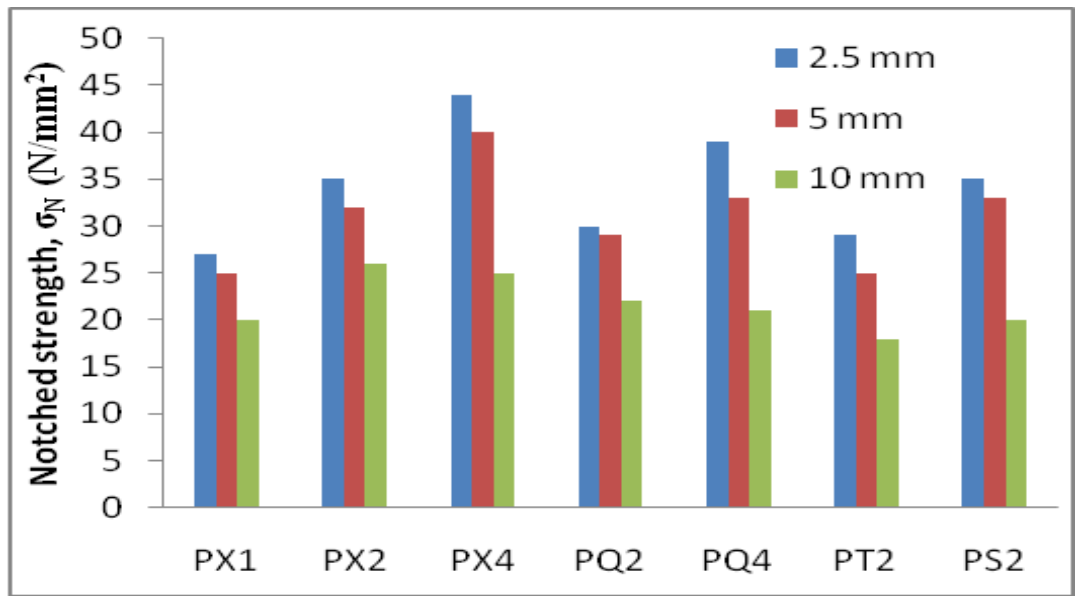

Fig. 3. Notched strength of all testing series conducted 
It is obvious that cross-ply lay-up demonstrated higher notched strength as compared with equivalent quasi-isotropic lay-up. It is important to note that $0^{\circ}$ is the optimum fibre direction to carry loading stress as the plate is subjected to remote tensile loading. Bear in mind that each woven fabric layer consists of two sets of orthogonal plies which equivalent to two unidirectional plies. Cross-ply lay-up consists of more $0^{\circ}$ plies compared to equivalent quasi-isotropic lay-up of similar plate thickness. Therefore, higher notched strength in cross-ply lay-up is perhaps not surprising. The average measured plat thickness of PX1, PX2 and PX4 are $0.7 \mathrm{~mm}, 1.8 \mathrm{~mm}$ and $3 \mathrm{~mm}$ respectively. About 10\% - 25\% increment of notched strength were observed with increment of woven fabric layer.

Better notched strength with larger plate thickness is contributed by extra resistance from interfacial strength from neighbouring layers to reduce occurrence of damage event from delamination. Again, the study of delamination damage event is outside the scope of current work, but high resistance to delamination as plate thickness increases was reported by previous researchers (Belmonte, [4]). He also found that constant micro-damage event occurred in the form of matrix cracking, delamination and fibre fracture through the plate thickness, portrays that higher resistance to damage as plate thickness increases. In reality, most composite components in civil engineering works are relatively thicker than any other engineering sectors. Therefore it is beneficial to study wide range of notched plate thicknesses to explore their structures response upon loading and applicability of these materials in structures application. It may exhibit more complex failure mode as the plates are getting thicker.

It was found that woven fabric CFRP [4] and GFRP [6] systems exhibited larger notched strength as compared with KFRP system. Kenaf fibre exhibited much lower modulus and tensile strength as compared with synthetic fibre. On the other hand, the carbon fibres and to the less extent glass fibre has higher stiffness, high tensile strength, low weight and high chemical resistance. Therefore, lower notched strength of woven kenaf fabric composite system were seen as compared to woven fabric synthetic fibres systems is much expected. However, as notched strength gives the value in the range if $18-44$ $\mathrm{N} / \mathrm{mm}^{2}$ is acceptable in low and medium load bearing application system. Although strength properties in carbon fibre system are much stronger but carbon fibres are much expensive in as it is considered as imported good. On the other hand, kenaf fibres are renewable, sustainable and much cheaper alternatives to synthetic fibres as it is grown locally. Bear in mind that the available notched strength datasets for synthetic fibres composites were conducted in large manufacturing factory scale, current study used inhouse fabrication techniques with limited resources, therefore finishing plates may not as good as in factory-manufactured plates.

\section{Conclusions}

It was found that better notched strength was exhibited by cross-ply lay-ups due to larger volume fraction of $0^{\circ}$ plies compared to equivalent quasi-isotropic lay-ups series. As expected, notched strength decreased with larger hole size due to larger unloaded region width prior to catastrophic failures. This is associated with process zone length where micro-damage event in the form of matrix cracking, delamination and fibre fracture occurred. Similar trends were found for plate thickness parametric study which notched strength were increased with thicker plates. Woven fabric kenaf fibres are renewable, sustainable and cheap materials gives alternatives to material designer to opt in low and medium load bearing applications.

The authors would like to be obliged to Universiti Tun Hussein Onn Malaysia for providing laboratory facilities and financial assistance under project Vot No. U245. 


\section{References}

1. V. Nair, P. Khosia, M. Ramachandran, Res. J. Pharm., Biol. Chem. Sci., 7(1), 2001 (2016)

2. L.S. Yee, H. Ahmad, MATEC web conf., 47, 1 (2016)

3. H. Ahmad, ARPN Journal of Engineering and Applied Sciences, 11(3), 1577 (2016)

4. H.M.S. Belmonte, C.I.C. Manger, S.L. Ogin, P.A. Smith, R. Lewin, Compos. Sci. Technol., 61, 585 (2001)

5. P.P. Camanho, P. Miami, $16^{\text {th }}$ International Conference on Composite Materials, Kyoto, Japan, (2007)

6. C.I.C. Manger, Failure of Notched Woven GFRP Composites: Damage Analysis and Strength Modelling, PhD Thesis, (University of Surrey,Guildford 1999)

7. N.A. Rahman, W. Tizani, Adv. Mat. Res. 1025-1026, 950 (2014)

8. N.A. Rahman, W. Tizani, T. Pitrakkos, J. Constr. Steel. Res., 93, 1 (2014) 